\title{
LA DISTANCIA ARTISTICA EN \\ LA HABANA PARA UN INFANTE DIFUNTO
}

POR

\author{
JOLANTA K. BAK \\ Harvard University
}

... si un parole se prétend vraie, elle devient fause. T. Todorov

Leer y descifrar los libros de Guillermo Cabrera Infante significa, en muchos casos, destruir sus órdenes aparentes para tratar de acercarse a la ambigüedad de su construcción. Así ocurría con Tres tristes tigres al nivel de la estructura global, asi ocurre con La Habana para un infante difunto (Barcelona: Seix Barral, 1979) al nivel de la frase, del capítulo, del texto entero. Leyendo esta novela de Cabrera Infante, guardamos una fuerte ilusión de que estamos participando en la creación del texto, puesto que presenciamos todo el tiempo el proceso de la escritura cuya visibilidad convierte, a su vez, la lectura en un proceso de percepción igualmente complejo. El autor no hace más que explorar las posibilidades de autorreferencialidad propias del género. Aunque el carácter autorreferencial de la novela parece haberse ritualizado como técnica literaria en la prosa contemporánea, no ha perdido su fuerza renovadora ni su función dinámica. Todavia convierte el texto en una búsqueda constante de su propia fórmula en que se ostentan y desmienten los procesos de la creación; manifestando las dificultades de la creación, el escritor desarrolla en el lector una suerte de desconfianza frente al lenguaje literario en general y frente a su propio texto. Las palabras dejan de ser transparentes y unívocas para volverse opacas y conflictivas. Su colocación en una narración no excluye las demás posiblilidades de su uso; al contrario, las incluye, agregando un rasgo de flexibilidad y apertura a la frase. Cabrera Infante desconfia fundamentalmente del lenguaje, pero lo hace a la manera de un glotón fascinado ante las posibilidades de la selección. De alli la presencia simultánea de diversas aceptaciones de una voz, de allí la busca de la palabra exacta, de allí los comentarios frecuentes acerca de los cambios del vocabulario habanero a lo largo del tiempo. Se ha hablado mucho del así llamado "barroco cubano", ese esfuerzo por crear un estilo manierista en el contexto de la prosa contemporánea que está presente en los mayores escritores de la Isla. Aunque asimismo un Lezama Lima, o un Carpentier, o un Cabrera Infante participan en esa fiesta de la palabra, cada uno lo hace de un modo muy distinto. Si en Lezama Lima lo "barroco" (prefiero la expresión amanerado o manierista) está en la 
construcción de la metáfora; si en Carpentier se traduce en una creación consciente de un estilo tal como lo entendia Flaubert, en Cabrera Infante lo manierista se sitúa del lado de la parodia, de la paronomasia y de la selección meticulosa du mot juste que luego se averigua como precisamente injusie. Si Carpentier o Lezama parecen crear una especie de acto de magia a base de palabras, Cabrera enseña toda la indumentaria del shamán. El manifestar el proceso creativo significa aproximar al lector al taller del escritor, hacerlo testigo de la gestación y el nacimiento del texto, invitarlo al diálogo. Y aunque acabemos por conocer las reglas del juego, no dejaremos de gozar de él puesto que esa desconfianza alegre frente al lenguaje nos ha contagiado y hemos aprendido a percibir una suerte de distanciamiento permanente frente a lo escrito, distanciamiento que convierte lo ya leído en otra cosa.

Aunque la frase sea una unidad acabada, no deja de ser una unidad abierta, por lo menos siempre que exista la posibilidad de su corrección, de rectificación, de matización. En un momento, el narrador pregunta: "¿Por qué no nos sentamos un ratico?", pero inmediatamente después comenta acerca de las consecuencias artísticas que pueda tener la frase anterior para el texto que se está escribiendo: "Me molestó a mí mismo el empleo del diminutivo pero lo que quise decir es que no estaríamos tanto tiempo sentados allí como para permitir a la oscuridad descender sobre nosotros, imponiéndonos su presencia proxeneta. (Ahora puedo burlarme de la prosopopeya pero entonces casi pensé en esos términos)" (p. 281). La rectificación de lo escrito es, pues, constante así que la. frase puede cambiar de valor y sentido en la medida en que está seguida por otra que la afine, la parodie o la contradiga.

El uso frecuente de la paronomasia no tiene el objetivo de demostrar el ingenio del autor (o mejor dicho, no tiene exclusivamente este propósito) sino de manifestar lo convencional que es el lenguaje $y$, más que nada, de explotar su valor lúdico. Las frases que hacen reír se multiplican a lo largo de la narración, que nunca pierde del todo el tono burlón y chistoso tan propio de los libros de Cabrera Infante. Que sea mediante la aliteración o la anáfora, que sea un juego de contigüidad fonética o una transcripción fonética con otro significado, de cualquier modo la escritura de La Habana es risible y la lectura, por consiguiente, se convierte en una actividad lúdica, una actividad que pertenece al dominio olvidado del placer.

La palabra en el texto de La Habana es una palabra enriquecida por el bagaje sincrónico y diacrónico de sus usos, cargada de diversos significados, envejecida por su aparición en otros textos literarios. Todas sus dimensiones tienden a aparecer a la vez, todas las connotaciones quieren estar presentes:

... para escurrirse a lo largo de la tapia (mejor el muro, por las connotaciones que la palabra tapia tiene con el cementerio y con la mucrte: allí atrás de aquella alta pared estaba la vida, o por lo menos, lo contrario a la muerte) ... (p.456). 
Como nada parece definitivo, lo interesante no es lo dicho sino lo que se está diciendo. Si el contexto no determina del todo el sentido de una voz, hay que delimitarlo explícitamente:

... pero cuando ella se puso de espaldas a la ventana, a la noche y a mi, su cabellera (esta palabra no la usa nadie en serio desde los tiempos clásicos, cuando, singularmente, las mujeres solían ser animales maravillosos, preciosos, unicornios de marfil: es precisamente por esto que la uso, que la he usado, que la usaré al hablar de ella) ... (p. 411).

La historia y la riqueza de la palabra están reflejadas en la distancia con que el narrador las emplea y si es el narrador quien va constantemente meditando acerca del lenguaje, el lector no puede menos que contagiarse de su actitud para desarrollar en sí mismo una suerte de desconfianza frente al texto. Tiene que estar pendiente de las continuas revaloraciones de lo escrito, es más: él mismo no puede dejar de cuestionar el significado y significante de lo que está leyendo. El texto le niega la pasividad, imponiéndole una lectura difícil, descifradora, distante y creativa en última instancia.

Si el uso de una voz "sacada del diccionario" resulta problemático, es aún más difícil tratar con su cargazón artística debida a su pasado literario. Esta dimensión, la dimensión intertextual, también está presente en el lenguaje de La Habana. La narración establece constantemente una especie de diálogo con otros textos, lo que crea una cierta tensión entre el libro y el sistema literario que lo respalda y contradice a la vez. El marco referencial se traslada claramente de la realidad mimética al cosmos verbal y el libro se auto-sitúa dentro del paradigma literario y también de otras disciplinas del arte. El ubicar la acción en un contexto "artístico" justifica la abundancia de motivos intertextuales, ya sean los cuadros, los espectáculos o las películas que funcionan como textossignos a los cuales se va refiriendo el narrador.

El humor y la intertextualidad quizás son las dos formas más notables de distancia respecto al lenguaje literario ya que, como dice Leo Spitzer, "les mots de T'autre' sonnent toujours dans notre bouche comme des mots dont nous ne voulons pas, très souvent avec une intonation de persiflage, d'outrance, de moquerie .... ${ }^{n_{1}}$. En la mayoría de los casos, el segundo uso de un signo está lleno de intención parodística tal como el libro entero es una parodia de la literatura "casanovesca". Sería redundante recordar el talento burlesco del autor de Tres tristes tigres en que se encuentra una de sus muestras más logradas; me refiero a las siete versiones de la muerte de Trotski. Ese matiz irónico o burlesco define mejor que nada el tipo de distanciamiento artístico que opera a lo largo de La Habana, cuyo mismo título nos introduce a ese mundo de parodias más o menos inocentes, de nostálgico humor y, sobre todo, de mucha auto-ironia. Mientras

${ }^{1}$ Leo Spitzer citado por Michaíl Bachtín en Les problèmes de la poélique de Dostö̈evski (París: L'Age de l'homme, 1970) 226 . 
la Pavana... de Ravel se convierte en la Habana del título, el retruécano apunta hacia el motivo de un tropicalismo algo meloso de la pieza musical, que resuita ser parodia de otra obra a su vez. La infanta está reemplazada por el infante, o mejor dicho, por Infante cuya muerte se deba tal vez al alejamiento de sis Habana recordada en la patética foto de la portada del libro. El título, sin dejar de tener sus connotaciones de patetismo barato y trivial, contiene también un motivo trágico: el papel que desempeñan el narrador y el autor implícito de la novela. Con esa misma actitud de distancia nostálgico-humorística se refiere el narrador a los recuerdos que constituyen la historia de La Habana.

El narrador-protagonista anónimo está contando su vida amorosa desde una perspectiva de distancia no sólo en términos de tiempo y espacio sino de experiencia vital y conciencia artística. La novela, concebida como monólogo, se convierte en una suerte de diálogo entre el yo que experimenta las cosas y el yo que las cuenta años después. La memoria funciona a la manera de un filtro que permite seleccionar y revalorizar los hechos. Ese proceso de revalorización de un pasado, que viene a ser una de las empresas artísticas fundamentales en el libro, reemplaza el monólogo con un diálogo entre un ser adolescente y un narrador adulto y experimentado. El narrador de La Habana, a diferencia del de Joyce en El retrato de un artista adolescente, intenta situarse dentro del pasado, escenificarlo, participar en él otra vez, pero sin perder nunca su punto de vista del presente. Toda literatura está hecha en cierta forma a base de la nostalgia por el pasado (aunque sólo de Proust, en adelante, de una manera explícita); toda escritura procura recobrar ese pasado, revivirlo, rehacerlo, volverlo presente y tangible. Sin embargo los tratamientos del pasado varian notablemente según los objetivos literarios de escritor. La Habana podria si tuarse en la línea de la distancia humoristica que trata de encubrir la inmensa nostalgia que late por debajo de la narración. La desconfianza ante el lenguaje que proporcionan los medios expresivos se convierte en una especie de distancia frente al recuerdo mismo, frente a la memoria, frente a lo que se está escribiendo y quedando como libro.

Sobre todo al principio de la novela hay un esfuerzo por mantener una cronología documental que se va perdiendo, poco a poco, cada vez que los saltos que da la memoria se hacen más incontrolables. Sin embargo el narrador, consciente del peligro de perder la distancia respecto al pasado, rectifica a menudo el orden de los recuerdos: "... pero ese recuerdo pertenece al futuro, hablo del presente, es decir del pasado" (p. 236). Y aunque los tres tiempos tienden a aparecer simultáneamente, el narrador los va cortando en unidades discretas para asegurarse a si mismo y asegurar al lector de que no está confundiendo el presente de la escritura con un pasado "real" e irrecuperable: "... asombrados ante el futuro, ahora el pasado" (p. 180). El viaje hacia atrás se hace desde el punto de partida del presente; sin embargo es este presente que queda fuera de la narración, a no ser el instante mismo de la creación, incluido de algún modo en el texto, su producto. 
El diálogo con el pasado no sólo permite rescatarlo mediante el lenguaje sino revalorizarlo y descubrir sus limitaciones. El narrador dividido en dos, el tímido don Juan de las aventuras juveniles y el adulto escritor, logra una suerte de polifonía dentro del texto en que su voz no suena como una voz autoritaria sino más bien llena de dudas y preguntas. Existe algo como un eco que siempre puede corregirla o rectificar lo que acaba de decir. Es la interpretación constante de lo recién escri to junto con la revaloración del pasado que le agregan al libro de Cabrera un cierto aire de apertura, le dan su aspecto de una obra en proceso, sobre la marcha todavia.

Esa polifonía responde a la imposiblidad de reconstruir un pasado de un modo fiel y exacto puesto que la memoria resulta un registro muy imperfecto. Solamente a través de la escritura, eso ya lo sabía Rousseau, en el mismo proceso creador, el pasado se hace presente, un presente universal, muy diferente de los contornos de un presente circunstancial. La rectificación de la cronologia compaginada con la perspectiva de un narrador experimentado es en $L a$ Habana una mise à nu del proceso de la creación literaria en la medida en que refleja el proceso de la conversión de lo documental en ficción. Como el lenguaje literario es la sustancia, los recuerdos van perdiendo su dimensión vital e inmediata pues están falsificados en función de las exigencias lingüísticas. Por mucho que intente el narrador resituarse en el pasado, será siempre en un pasado de palabras, anacrónicas además respecto al hecho referido: “... (la frase pertenece al futuro, a la Habana y a la alta adolescencia: la palabra contemporánea era singar)" (p.54). En la medida en que la escritura convierte un pasado concreto en un presente literario universal, el protagonista del final del libro no se iguala con el de las páginas iniciales. El tono realista y autobiográfico cede cada vez más a los vuelos de una fantasía desconcertante que desemboca en un final freudiano y arquetípico en que el protagonista logra la unión primaria con la mujer, la mujer confundida con la madre cuyo vientre le ofrece el refugio definitivo como en los primeros días de su existencia en forma de feto. Lo que presenciamos a lo largo del libro es el proceso de la creación del personaje que acaba por suplantar el proyecto inicial de una novela autobiográfica y "documental". Dicho sea de paso que toda literatura de ese tipo que aspire a la trascendencia artística tiene que seguir el camino de la transformación del material documental en materia literaria. De algún modo, la continuidad de la narración tiene que oponerse a la discontinuidad de los personajes (que en el caso de La Habana pretende ser uno solo) que van poblando el mundo narrado.

Esas diversas formas de distancia artística convierten la última novela de Cabrera Infante en una obra polifónica, abierta aunque acabada, dinámica, llena de sorpresas, en suma, en una novela que transgrede sus propios límites. Nada parece definitivo mientras la estamos leyendo pues todo puede ser alterado por la frase o la palabra que sigue. El auto-cuestionamiento acerca del proceso de la escritura, que está presente en cada página, nos impone una actitud crítica, desconfiada y distante ante la lectura misma. 
La Habana para un infante difunto desarrolla uno de los temas más problemáticos de la cultura que es el del erotismo. A pesar de los cambios notables de mentalidad que han tenido lugar a lo largo de nuestro siglo (sobre todo en el mundo de la tradición anglo-sajona), lo erótico sigue siendo un tema rodeado de un cierto halo de tabú. Y aunque el erotismo, como una de las dimensiones fundamentales del ser humano, deberia, al contrario, ocupar un lugar privilegiado entre las preocupaciones intelectuales, ha quedado más bien como una suerte de fenómeno subterráneo, clandestino. Por consiguiente, nuestro lenguaje, tanto cotidiano como artístico, carece del aparato expresivo para hablar del erotismo abierta y francamente. Hemos desarrollado esencialmente tres tipos de lenguaje relativo a este fenómeno: el científico cuyo uso está reducido a un estrecho circuito de especialistas, el lírico o cortesano de fuerte matiz metafórico y, finalmente, el así llamado lenguaje vulgar luego condenado a estar fuera de la norma lingüística aceptada. En cuanto al lenguaje artístico, ha prevalecido indudablemente la vertiente culta cuyos orígenes se remontan a la lírica cortesana medieval; ésta creó todo un código metafórico y metonímico, a fin de poder expresar los aspectos carnales del amor tradicionalmente relacionados con el pecado. Es en esa vertiente "dignificadora" que se ha escrito gran parte de la literatura erótica, por lo menos en lengua española. Mientras la literatura carecía (salvo unos ejemplos brillantes en la antigüedad, en el renacimiento y otros tantos) y aún carece de un verdadero lenguaje erótico, en el habla cotidiana la fantasía popular ha incorporado innumerables voces y expresiones (su cantidad varía sensiblemente según distintas lenguas) para llenar la laguna que existe en la norma culta. La aparición infrecuente del léxico "vulgar" en los textos literarios se ha considerado a veces escandalosa, otras exótica, la que añadía sabor al relato. Ese lapso en cuanto al desarrollo del lenguaje erótico sigue siendo notable, pues Petronio, Boccaccio y de Sade pertenecen todavía a una corriente minoritaria. La laguna resulta aún más honda en la literatura de tradición hispánica en que el puritanismo de una fuerte raigambre católica de un Camilo José Cela no ha sido del todo suplantado por los intentos de ciertos escritores hispanoamericanos como Cortázar, Puig, Donoso.

En este contexto, el nuevo libro de Cabrera Infante aparece como un esfuerzo a la vez admirable y solitario en busca de un auténtico lenguaje erótico del cual carecen las letras hispánicas. La Habana representa un intento por modificar las normas literarias para que respondan a la evolución de las normas socio-culturales que ha tenido lugar por ejemplo en España después de la muerte de Franco. El mismo autor afirmó que había escrito La Habana un poco notando la liberalización erótica de la España pos-franquista ${ }^{2}$. La búsqueda o

${ }^{2}$ En la conferencia organizada en Yale University el día 16 de abril, 1980. 
la creación de un nuevo lenguaje erótico, presente a lo largo de La Habana, se basa también en cierta forma de distancia frente a la tradición literaria en que se reconcilian la continuidad y el cambio. El lenguaje culto, cortesano, metafórico, está sabiamente parodiado y mezclado con lo comúnmente llamado vulgar o trivial, originando una manera de hablar propia y hasta ahora. desconocida.

Este libro está concebido al modo de memorias eróticas de un narradorprotagonista anónimo que trata de reconstruir gran número de sus aventuras desde los tiempos de la adolescencia hasta la primera madurez. Su modelo o inspiración remota podrian haber sido las novelas pornográficas que proliferaron en la Cuba de los años cuarenta y de las cuales el autor era un ávido lector, sin embargo el paralelo se detiene en lo más superficial de la estructura del libro. Lo demás es justamente la distancia artística que convierte La Habana en una gran novela. El epígrafe del libro: "Blondes seem to be pretty scarce here", tomado del guión de King Kong, introduce la cacería de las rubias como marco de las innumerables incursiones del insaciado protagonista. La referencia a la caza amorosa vincula ese marco con toda una tradición literaria ritualizada en forma de tópico; sin embargo se trata más que nada de su parodia, de una burla en que lo "culto" se mezcla con lo trivial y cómico, en que el antiguo tópico se aproxima a la creencia popular de que las rubias resultan más atractivas en los paises tropicales. Efectivamente, a lo largo del texto aparecen varias rubias que el narrador persigue casi obsesivamente convirtiendo la caza metafórica en una caza real en que la posesión de la acosada da cumbre a la aventura. El tópico queda así despojado de todo su valor lírico y sólo designa un desnudo deseo machista de poseer a la hembra o a varias hembras (freudianamente hablando en una búsqueda insatisfecha de la madre, en que el horror ante el incesto se mezcla con un fuerte deseo erótico) sin siquiera contemplar su belleza, sin deleitarse verdaderamente en su cuerpo. En todas las aventuras que preceden el encuentro con Julieta, hay un inminente rechazo al cuerpo femenino, lo que causa en parte el constante fracaso erótico del protagonista. Ese comportamiento no solamente parodia al cazador de la lírica medieval sino también a una cierta tradición más contemporánea, encarnada en el protagonista mismo de la novela.

Del mismo modo funcionan otros resabios del "género" erótico, tal el donjuanismo (un donjuanismo paródico dada la timidez del Don Juan, un donjuanismo superado por la irónica victoria por el amor, en que el protagonista se deja "domar" por una mujer imperfecta, una amazona de seno mutilado), el voyeurismo, el rascabucheo en los cines y otros tantos. De esta manera, en $L a$ Habana se confrontan constantemente el texto y el sistema literario creando una sabrosa tensión artística que nos obliga a reemplazar una lectura lineal con los saltos de la intertextualidad. Allí está la distancia que la narración va marcando frente al bloque de textos que la respaldan, que la hacen en cierta manera posible. 
El antiguo aparato expresivo recibe también un tratamiento paródico en la medida en que lo altamente lírico está salpicado de humor mientras que lo púdicamente considerado vulgar está de algún modo dignificado. La galería de las mujeres que desfilan en la memoria del narrador está a menudo descrita en tonos exaltados, especialmente cuando se trata de un primer encuentro que se debe en general a la fascinación con la belleza, que desde luego puede resultar ilusoria. Esa actitud reverencial ante la hermosura se nota con más claridad en los episodios dedicados a Julieta y a Margarita en que la mujer vuelve a situarse en su lugar privilegiado de la dama, de la musa, de la madre que hay que loar de una manera exaltada: ... le digo: No, gracias a tî́, y debí agregar gracias por haberme permitido acostarme por primera vez con una mujer, gracias por tu belleza, gracias por haber repetido esa ocasión que será única, que recordaré toda mi vida, que agradeceré siempre, que lo estoy haciendo todavia ahora cuando ha pasado más de un cuarto de siglo de esa iniciación inigualable" (p.376). Aunque las protagonistas femeninas, detenidas por el recuerdo, se convierten en tableaux vivants, en cuadros, en fotos, en secuencias cinematográficas, no pueden permanecer asi pues la actitud irónica del narrador las va a desacralizar pronto. Si al comienzo de "La visión de un mirón miope" se da una bella estilización del mito de Elena en un lenguaje al tamente lírico, el final del episodio, sorpresivo y grotesco a la vez, funciona como una especie de contrapunto irónico en el que se destruye bruscamente el espectáculo visualizable recién creado. Es como si el narrador experimentado se opusiera de repente a las rêveries del joven que lo estaba viviendo. Es también uno de los momentos en que el que escribe nota la insuficiencia del lenguaje tradicionalmente considerado erótico y tiene que apartarse de él, tanto por el camino de la distancia, por el del humor y de la parodia, como mediante la incorporación de lo "vulgar".

Junto con su intento de rescatar un pasado, emprende Cabrera Infante el rescate de lo trivial, de lo popular, de lo vulgar y en su Habana, registra y usa todo un lenguaje lleno de vitalidad y fantasía cuya aparición en un texto artístico lo traslada forzosamente a otro nivel del sistema lingüístico. Sin embargo esa conversión de lo vulgar en materia artística resulta igualmente problemática porque "si en vez de amor hablamos de sexo encontramos que la vulgaridad es rampante aun en la nomenclatura actual o popular." (p. 529). El hecho de que se trata de un narrador protagonista ayuda a convertir esa empresa en un verdadero logro artístico. Puesto que al borrar las distancias entre la acción y la narración (guardándolas a otro nivel), el narrador puede evitar en gran parte los juicios valorativos, esto a su vez tiene su impacto en el lector que tiende más fácilmente a identificarse con su punto de vista, puesto que se trata de algo "vivido" y experimentado por la persona literaria cuyas aventuras comparte. Así aceptamos, por ejemplo, la pervertida geografía humana del solar en que vive el protagonista sin mucha resistencia, porque el narrador nos hace creer que él mismo era parte de "la casa de las transfiguraciones". 
El elemento dinámico de La Habana es el hecho de que ni siquiera la mezcla de lo lírico con lo vulgar puede definir el lenguaje de la novela porque se trata de algo más, se trata sobre todo del mismo proceso de escritura que no deja de ser una aventura, siempre sobre la marcha, en cambio y auto-rectificación constante. Son más bien esas distintas formas de distancia artística (en gran parte, parodística) respecto a lo escrito, o más bien a lo que se está escribiendo, que generan esa nueva manera de hablar de "actos inocentes con palabras culpables".

\section{III}

La Habana como libro de memorias eróticas encubre otros recuerdos que forman el trasfondo de la narración, que pertenece en su totalidad a la literatura de la nostalgia, a la literatura del exilio. Ese marco del exilio hace que la narrativa de Cabrera Infante gravite invariablemente hacia un pasado ligado intimamente con Cuba, con un espacio creativo primario que fue desplazado o alterado cuando el autor dejó el país. El aferramiento al tiempo-espacio perdido es $\sin$ duda característico de la literatura de destierro en que la distancia en el espacio se confunde a menudo con la distancia proustiana en el tiempo. La reconstrucción de los recuerdos eróticos en el libro de Cabrera Infante es no sólo un pretexto para aproximarse, sino para recuperar un pasado vinculado con un determinado lugar. El tema erótico no impide que por debajo, clandestinamente casi, yazga esa preocupación esencial. Por lo tanto, el personaje secreto, pero quizás más palpable de la novela, es la ciudad cuya función está lejos de ser un escenario porque representa todo un modo de vivir de una época dada. Las descripciones meticulosas de la arquitectura habanera, de las calles, del Malecón, de la vida nocturna, de la lluvia y del mar, todas ellas permiten acercarse a lo definitivamente perdido, permiten acercarse a esta "isla dentro de la isla" que se ha transformado en el recinto favorito de la memoria. El exilio está determinando la vida del protagonista a lo largo del libro en la medida en que ya la experiencia inicial del pasar del campo a la ciudad es su preludio para entrecruzarse luego con el destierro de la infancia a la adolescencia. Del mismo modo en que la nostalgia del pueblo y luego de la Habana representan dos fases distintas del exilio en términos espaciales, la búsqueda del cariño y amparo de la madre (mezclada por lo tanto con el terror ante el atractivo sexual que la figura de la madre va a tener para el protagonista) es su equivalente en términos del tiempo. La ciudad y la adolescencia son los dos momentos capitales en la "educación sentimental" del protagonista, una educación que, como en Vargas Llosa y en Gombrowicz, más se asemeja a un proceso de depravación. La perspectiva desde la cual se está analizando ese período de la vida del protagonista permite notar sus limitaciones, tal un erotismo precoz, la vulgaridad grotesca que le servía de escenario, los prejuicios familiares, todo lo que iba a desembocar en la fracasada vida amorosa del adulto adúltero. 
A esta primera experiencia de destierro se sobrepone la segunda, la que enmarca la totalidad del texto pero que queda excluida de los límites de la narración y figura como una simple acotación anecdótica escrita en cursiva al final del libro: "Londres, 1975-78". El exilio se vuelve concéntrico cada vez que las experiencias del que experimenta, las del que narra y las del autor implícito se confunden. Es la perspectiva del niño desterrado del paraiso de la infancia, del adolescente que lo deja de ser en algún momento, de Cabrera Infante finalmente, que le da al texto ese sabor amargamente dulce de la nostalgia, que justifica sus saltos temporales, que origina el tono autobiográfico en que está escrita La Habana. Sin embargo, la experiencia del exilio, por dolorosa que sea, es provechosa a la vez puesto que posibilita esa suerte de distancia frente a los hechos vividos que se pueden interpretar, juzgar, reivindicar. La experiencia del protagonista de La Habana recibe así una valoración nueva, la de un artista, la de un escritor que entabla un diálogo con su propio pasado. Esa valoración vale asimismo para la experiencia colectiva de una determinada generación de personas educadas en una cultura de raices hispánicas. El que cuenta en Lo Habana no lo hace nunca en un tono autoritario, tal como lo hizo Proust, sino mira su pasado con tolerancia, humor, indulgencia. Es esta luz del presente que impide que el texto se convierta en una alabanza incondicional de la época precastrista en Cuba o que el protagonista tenga la trágica ilusión de poder revivir el pasado como tal. Las memorias, aunque empapadas del mal du pays, no impiden ver una adolescencia traumática en la Habana de los años cuarenta, una ciudad llena de pobreza, poblada de prostrbulos, con una población desesperadamente hedonista, de algún modo pre-revolucionaria. Del mismo modo que en TTT el pasado wo era únicamente identificable con el pintoresco choteo de una Habana nocturna, La Habana redescubre el vacío existencial que vislumbraba detrás del desenfrenado erotismo.

Sin embargo el melancólico "mirón miope" de la portada del libro está tratando de ver un espacio en blanco, poblado únicamente de recuerdos perecederos o de fugaces imágenes cinematográficas. Los recuerdos se van distanciando del presente cada vez más y se van sobreponiendo los pasados tal como en la foto de la cubierta, el pasado de la Habana prerrevolucionaria (con su hotel Inglaterra) se sobrepone a uno aún más remoto, con su anacrónica cámara del siglo pasado. La nostalgia que se desprende de la foto es por todos los pasados, por le temps perdu en general. El recuerdo desvencijado y descolorido como las antiguas fotografías puede sin embargo recobrar toda su frescura gracias al lenguaje, gracias a la escritura como proceso que hace que se alteren los límites del tiempo. La respuesta que el escritor encuentra a la pregunta del protagonista: “ ¿... será que la memoria es imperecedera, que no es la vida, que el recuerdo puede salvar de la muerte?" (p. 595) consiste en la aventura que presenciamos, la del rescate del pasado mediante la escritura, ejercicio que lleva a una felicidad comparable con la del acto de la masturbación 
(conexión ya advertida por Rousseau). Sólo mediante el lenguaje el pasado puede cobrar una apariencia del presente, de un presente atemporal propio de la escritura y de la lectura, en la medida en que "in all instances an absence must be met at the moment of the writing and through the process of the writing, the dialectical progress of the poem ${ }^{m}$. En el proceso de la escritura, el recuerdo se va materializando $\mathrm{y}$, al superar las limitaciones de una anécdota, se convierte en auténtica sustancia artistica. Es el oficio literario que permite a un desterrado superar las coordenadas del exilio ofreciéndole un nuevo modo de aprehensión del mundo y de su propia condición. El pasado no es más una sepultura del tiempo, sino una relación presente entre el escritor y el lector, una relación mediatizada por los procesos de escritura y lectura del texto. El "pasado muerto" y el "porvenir helado" se eternizan en un presente universal de la tradición literaria. De allí, la fiesta del lenguaje en Cabrera Infante, de allí su desconfianza frente a esa misma materia lingüística, de allí su escritura amanerada en que el escritor encuentra su respuesta al destierro, al olvido, al tiempo perdido.

Como dice Salinas, "abrazado a mi idioma como a incomparable bien ...".

${ }^{3}$ Claudio Guillen, "On the Literature of Exile and Counter-Exile", Books Abroad (Spring 1976): 271-281. 
